International Journal of Biological Sciences

ISSN 1449-2288 www.biolsci.org 2006 2(3):117-124

Research paper

C2006 Ivyspring International Publisher. All rights reserved

\title{
S-nitrosogluthathione reductase activity of amphioxus ADH3: insights into the nitric oxide metabolism
}

\author{
Laura Godoy, Roser Gonzàlez-Duarte and Ricard Albalat
}

Departament de Genètica. Facultat de Biologia. Universitat de Barcelona. 08028 Barcelona, Spain.

Corresponding address: Ricard Albalat, Departament de Genètica, Facultat de Biologia, Universitat de Barcelona. Av. Diagonal, 645. 08028 Barcelona, Spain. Tel.: +34.934029009; Fax:+34.934034420; E-mail: ralbalat@ub.edu

Received: 2006.02.06; Accepted: 2006.04.09; Published: 2006.05.05

Nitric oxide (NO) is a signalling molecule involved in many physiological functions. An important via of NO action is through the S-nitrosylation of proteins, a post-translational modification that regulates the activity of enzymes, protein-protein interactions and signal transduction pathways. Alcohol dehydrogenase class III (ADH3) recognises S-nitrosoglutathione (GSNO), the main reservoir of non-protein S-nitrosothiol, and functions as an effective GSNO reductase (GSNOR) and as a safeguard against nitrosative stress. To investigate the evolutionary conservation of this metabolic role, we have produced recombinant Branchiostoma floridae ADH3. Pure preparations of ADH3 showed 2-fold higher activity as GSNOR than as formaldehyde dehydrogenase, the previously assumed main role for ADH3. To correlate ADH3 expression in the gut with areas of NO production, we analysed the tissue distribution of the nitric oxide synthase (NOS) enzyme in amphioxus larvae. Immunostaining of the NOS enzyme revealed expression in the gut and in the dorsal region of the club-shaped gland. Co-localization in the gut supports the ADH3 and NOS joint contribution to the NO/SNO homeostasis.

Key words: Cephalochordate, alcohol dehydrogenase class III (ADH3), nitric oxide synthase (NOS), intestine, club-shaped gland.

\section{Introduction}

Nitric oxide (NO) is a diffusible highly reactive gas produced by the enzymatic conversion of Larginine by nitric oxide synthases (NOS). NO possesses an unusually large repertory of physiological functions and it is probably one of the oldest bioregulatory systems controlling metazoan physiology [1]. In addition to the well-documented roles of NO in vertebrates (reviewed in [2]), many studies also support the functional relevance of $\mathrm{NO}$ in invertebrates [3-8]. Classically, NO action had been associated with the cGMP signalling pathway. However, the current picture points to additional mechanisms for NO bioactivity such as S-nitrosylation of cysteine thiols (SNO) [2, 9], a post-translational protein modification that regulates the activity of metabolic enzymes, structural proteins or transcription factors [10]. Although specific enzymatic mechanisms involved in protein S-nitrosylation have not yet been described, degradation of Snitrosoglutathione (GSNO) promotes the denitrosylated state and so, GSNO turnover, significantly influences the level of whole-cell Snitrosylation.

GSNO is mainly degraded by an NADHdependent S-nitrosoglutathione reductase (GSNOR) activity [11], associated to the medium-chain alcohol dehydrogenase class III (MDR-ADH3) enzyme, also known as glutathione-dependent formaldehyde dehydrogenase (FALDH) [11-14]. ADH3 enzymes had been involved in formaldehyde metabolism, oxidising S-hydroxymethylglutathione (HMGSH) to Sformylglutathione [15]. However, the high specificity of $\mathrm{ADH} 3$ towards GSNO [12] and the fact that yeast and mouse ADH3 knockouts devoid of GSNOR activity show a substantial increase of S-nitrosylated proteins $[9,11]$ have established a direct relation of ADH3 with NO metabolism.

$\mathrm{ADH} 3$ enzymes have been identified in most major life forms, ranging from bacteria to animals. ADH3 is the only member of the MDR-ADH family found in non-vertebrate organisms, and is considered the archetypal form from which multiple gene duplications expanded the vertebrate $\mathrm{ADH}$ family into at least eight different classes (ADH1-8) (reviewed in [16]). In previous studies, we showed that in contrast to the widespread expression pattern of the vertebrate $A d h 3$, the expression of the $A d h 3$ in non-vertebrate organisms (e.g. arthropods, ascidians and cephalochordates) is restricted to the digestive system $[17,18]$. This finding suggested that the ADH family expansion during early vertebrate evolution was accompanied by a change in the $A d h 3$ expression pattern, and challenged the role that had been classically attributed to $\mathrm{ADH} 3$ as a housekeeping enzyme in charge of formaldehyde elimination [18]. In this work, we provide the first evidence that $\mathrm{ADH} 3$ might be involved in NO homeostasis in the cephalochordate Branchiostoma floridae. Pure preparations of recombinant amphioxus ADH3 showed in vitro the ability to reduce GSNO, indeed a 
better substrate than HMGSH, the intermediate product in formaldehyde metabolism. Moreover, to correlate $\mathrm{ADH} 3$ expression with $\mathrm{NO}$ production, we have performed immunostaining of NOS in developing larvae, and showed $\mathrm{ADH} 3 / \mathrm{NOS}$ colocalization in mid- and hind-gut areas.

\section{Materials and Methods}

\section{Electrophoresis and enzymatic activity staining of crude extracts}

To detect GSNO reductase and formaldehyde dehydrogenase activities, six amphioxus adults were homogenized in $2 \mathrm{ml}$ of degassed $0.1 \mathrm{M}$ sodium pyrophosfate, $0.1 \mathrm{mM}$ DTT, and centrifuged at 20,000 $\mathrm{g}$ for $20 \mathrm{~min}$. Protein concentration of the crude extracts was determined colorimetrically. Enzymatic activity was assessed after electrophoresis on nondenaturing $7.5 \%$ polyacrylamide gel. For formaldehyde dehydrogenase activity, gels were incubated in $0.1 \mathrm{M}$ sodium pyrophosphate $\mathrm{pH}$ 8.0, 0.5 $\mathrm{M} \mathrm{KCl}, 1 \mathrm{mM}$ reduced glutathione and $5 \mathrm{mM}$ formaldehyde at $37^{\circ} \mathrm{C}$ [19]. After 5 minutes, nitroblue tetrazolium and phenazine methosulfate were added at a final concentration of $0.1 \mathrm{mM}$ each. For GSNO reductase activity, gels were incubated in $0.1 \mathrm{M}$ sodium pyrophosphate at $\mathrm{pH} 7.4$ with $2 \mathrm{mM} \mathrm{NADH}$, for $15 \mathrm{~min}$ in an ice-bath [14]. Excess buffer was drained and gels were covered with filter paper strips soaked in GSNO. After $15 \mathrm{~min}$, the filter paper was removed and the gel was exposed under ultraviolet light to observe the disappearance of the NADH fluorescence.

\section{Expression and purification of recombinant $B$. floridae ADH3}

The full-length coding region of B. floridae Adh3 cDNA [17] was PCR amplified with the sense primer 5'-TTGGATCCATGGCGGACACTG-3', which introduces a $B a m H I$ restriction site (underlined) next to the ATG (in bold), and the antisense primer $5^{\prime}$ CGAATTCTCAGAAGTGGATCAC-3', which places a EcoRI site (underlined) at the $3^{\prime}$-end. The PCR conditions were as follows: an initial denaturation step at $94^{\circ} \mathrm{C}$ for $5 \mathrm{~min}$, followed by 40 cycles at $94^{\circ} \mathrm{C}$ for $45 \mathrm{~s}, 42^{\circ} \mathrm{C}$ for $1 \mathrm{~min}$ and $72^{\circ} \mathrm{C}$ for $2 \mathrm{~min}$ and a final extension step at $72^{\circ} \mathrm{C}$ for $5 \mathrm{~min}$. The purified fragment was digested with BamHI and EcoRI enzymes and cloned into the expression vector pRSETA (Invitrogen), to fuse a polyhistidine tag at the N-terminal of ADH3. The expression of His-ADH3 protein in E. coli BL21 (DE3) pLys was induced with $0.1 \mathrm{mM}$ isopropyl- $\beta$-D-thiogalactopyranoside for $3 \mathrm{~h}$ at $37^{\circ} \mathrm{C}$. Cells were harvested and disrupted by sonication in cold PBS. Protein extracts were collected after centrifugation at $20,000 \mathrm{~g}$ for $20 \mathrm{~min}$ at $4^{\circ} \mathrm{C}$ and His-ADH3 was partially purified with a Talon Metal Affinity Resin following the supplier's instructions (BD Biosciences Clontech, USA). Protein recovered after overnight treatment with enterokinase (EKMaxTM Enterokinase; Invitrogen) at $16^{\circ} \mathrm{C}$, was loaded in Superdex200 FPLC column equilibrated with $20 \mathrm{mM}$ TrisHCl $\mathrm{pH}$ 8.0. Formaldehyde/GSH activity was tested in the collected fractions. From 500 $\mathrm{ml}$ culture, $5 \mu \mathrm{g}$ of pure ADH3 was obtained with a specific activity with formaldehyde of $4.3 \mathrm{U} / \mathrm{mg}$. Protein concentration was determined colorimetrically and purity was analysed by SDSPAGE with Coomassie brilliant blue staining. Enzymatic activity of the purified recombinant protein was assayed in situ after electrophoresis as described in the previous section.

\section{Kinetic studies}

Formaldehyde dehydrogenase and GSNO reductase activities were tested at $25^{\circ} \mathrm{C}$ by monitoring the production of NADH at $340 \mathrm{~nm}\left(\varepsilon_{340}=6,22 \mathrm{mM}^{-1}\right.$ $\mathrm{cm}^{-1}$ ) for formaldehyde oxidation or the consumption of NADH and GSNO $\left(\varepsilon_{340}=7,06 \mathrm{mM}^{-1} \mathrm{~cm}^{-1}\right)$ for GSNO reduction. The formaldehyde dehydrogenase activity was measured at $\mathrm{pH} 8.0$ in $0.1 \mathrm{M}$ sodium pyrophosphate, with S-hydroxymethylglutathione (HMGSH; formed by mixing formaldehyde and glutathione) and $\mathrm{NAD}^{+}$. GSNO reductase activity was measured at $\mathrm{pH} 7.5$ in $0.1 \mathrm{M}$ sodium pyrophosphate, with freshly prepared GSNO and NADH. Kinetic constants for $\mathrm{NAD}^{+}$and $\mathrm{NADH}$ were determined with $1 \mathrm{mM}$ of glutathione $-1 \mathrm{mM}$ of formaldehyde, and with $0.3 \mathrm{mM}$ of GSNO, respectively. Kinetic constants for HMGSH and GSNO were determined with $2.4 \mathrm{mM} \mathrm{NAD}^{+}$and $0.3 \mathrm{mM} \mathrm{NADH}$, respectively. Kinetic constants were calculated with the non-linear regression program Grafit (version 3.0, Erithacus Software), and expressed as the mean \pm SD of at least three independent determinations. Catalytic constant (kcat) values were calculated using the protein molecular mass of 80,000 for the $\mathrm{ADH} 3$ dimer.

\section{Amphioxus NOS and phylogenetic analysis}

A B. floridae cDNA-NOS sequence was retrieved from GeneBank, accession number AF396968, and compared with available vertebrate and invertebrate sequences. The following NOS sequences were used in our study: AAK83069 (Aplysia californica, California sea hare), O61608 (Anopheles stephensi, mosquito), BAB85836 (Bombix mori, silk worm), CAB60197 (Cyprinus carpio, carp). XP_692103 and NP_571735 (Danio rerio, zebrafish), NP_523541 (Drosophila melanogaster, fruit fly), NP_990292 and XP_425296 (Gallus gallus, chiken), P29474, AAA36375 and P29475 (Homo sapiens, human), O61309 (Lymnaea stagnalis, great pond snail), O77104 (Manduca sexta, tobacco hornworm), P70313, AAM11887 and Q9Z0J4 (Mus musculus, mouse), CAC83069 (Oncorhynchus mykiss, rainbow trout), NP_068610, BAA07994 and P29476 (Rattus norvergicus, rat), Q26240 (Rhodnius prolixus, insect), XP_781703 (Strongylocentrotus purpuratus, sea urchin), AAM46138 (Takifugu poecilonotus). Frog sequences were taken from Xenopus tropicalis genome assembly 3.0 (JGI): fgenesh1_pg.C_scaffold_2000005, estExt_fgenesh1_pg.C_12630001_ and fgenesh1_pg.C_scaffold_456000016. Sequences were retrieved and corrected to maximize the similarity with known NOS enzymes. 
Protein sequence alignments and a neighbourjoining (NJ) tree were generated with clustalX [20] and drawn with the TreeViewPPC program [21]. Confidence in each node was assessed by 1000 bootstrap replicates. Maximun likelihood (ML) analysis was performed using the quartet sampling and NJ parameter estimation procedure of TREEPUZZLE. The N-terminal region of the NOS isozymes (neuronal, inducible and endothelial) are highly variable in length and sequence, and produced unreliable alignments. This region was, therefore, excluded from the phylogenetic analyses and only alignments starting at the oxygenase domain (D352 of human nNOS) were considered.

\section{Western blot and whole-mount immunostaining}

For western blot, four B. floridae specimens were homogenized in cold PBS, $0.1 \mathrm{mM}$ DTT and centrifuged at $20,000 \mathrm{~g}$ for $20 \mathrm{~min}$. $0.5-1.0 \mathrm{mg}$ of soluble protein was resolved on an SDS-PAGE and transferred into a polyvinylidene difluoride (PVDF) membrane. After $1 \mathrm{~h}$ in blocking buffer $(10 \%$ fat-free milk in PBS), the membrane was incubated for $1 \mathrm{~h}$ with a universal anti-NOS antibody (anti-uNOS, Affinity Bioreagents Inc.), at 1:1000 dilution in 0.5\% fat-free milk in PBS with $0.05 \%$ Tween-20. The antiuNOS antibody is an affinity purified rabbit anti-NOS directed against a C-terminal epitope (DQKRYHEDIFG) that is highly conserved among the different NOS isoforms in vertebrates, insects and crustaceans [22]. Immunoreactive proteins were visualized by ECL Western blotting analysis system (Amersham Biosciences) after incubation for $1 \mathrm{~h}$ with peroxidase-conjugated goat anti-rabbit secondary antibody used at 1:2000 dilution.

B. floridae larvae were collected, fixed, and stored at $-20^{\circ} \mathrm{C}$ in $70 \%$ ethanol. Immunostaining was performed as described [23] with minor modifications. Briefly, larvae were incubated in $1 \mathrm{ml}$ ethanol/DMSO (1:1) for $3 \mathrm{~min}$ in ice, followed by 15 min at RT after addition of $250 \mu \mathrm{l}$ Triton X-100. Larvae were rinsed 6 times, $10 \mathrm{~min}$ each, in TST $(20 \mathrm{mM}$ TrisHCl pH 7.4, $100 \mathrm{mM} \mathrm{NaCl}$ and $0.1 \%$ Triton X-100) and blocked for $30 \mathrm{~min}$ in TSTM (TST containing 5\% fat-free milk). The larvae were incubated for $48 \mathrm{~h}$ at $4^{\circ} \mathrm{C}$ in rabbit anti-uNOS (Affinity Bioreagents Inc.) (dilution 1:100 in TSTM). After rinsed $7 \times 20 \mathrm{~min}$, the secondary antibody, donkey anti-rabbit IgG labeled with Rhodamine-red (Jackson Immunoresearch), was added (dilution 1:200) for $48 \mathrm{~h}$ at $4^{\circ} \mathrm{C}$, and larvae were rinsed again $7 \times 20 \mathrm{~min}$. Finally, the samples were mounted using SlowFade light Antifade Kit (Molecular Probes) and observed by confocal microscopy (Leica TCS 4D).

\section{Results}

\section{GSNO reductase activity of amphioxus ADH3}

GSNO reductase activity was assessed spectrophotometrically in amphioxus homogenates, $4.2 \times 10^{-3} \mathrm{U} / \mathrm{mg}$. Non-denaturing gel electrophoresis of protein homogenates of whole adult animals showed a very similar banding pattern for GSNO activity and formaldehyde/GSH staining (Figure 1, lanes 1 and 2), suggesting that both substrates are metabolised by the same enzyme. To further investigate this possibility, the cDNA of $B$. floridae Adh3 was expressed in E. coli. The recombinant protein was produced and purified to homogeneity (Figure 1, lanes 3, 4 and 5). In the pure preparation, the GSNO reductase and formaldehyde dehydrogenase activities were shown by native gel electrophoresis staining (Figure 1, lanes 6 and 7). The specific activities of the purified recombinant ADH3 were quantified by monitoring the absorbance at 340 $\mathrm{nm}$ with GSNO (65.6 U/mg) and HGMGSH (4.3 $\mathrm{U} / \mathrm{mg}$ ) as substrates. The kinetic parameters of $B$. floridae ADH3 (Table1) were examined under conditions allowing comparisons with those obtained for other class 3 forms. The $\mathrm{Km}$ value for the recombinant $B$. floridae ADH3 in front of HMGSH was essentially the same as that for the native $B$. lanceolatum ADH3 [17], but the kcat value (375 $\left.\mathrm{min}^{-1}\right)$ was slightly lower than the one previously reported $\left(680 \mathrm{~min}^{-1}\right)$. The catalytic efficiency of the recombinant B. floridae $\mathrm{ADH} 3$ for GSNO reduction was twice that of HMGSH oxidation, indicating the preference for GSNO reduction of the amphioxus enzyme. Yeast and human $\mathrm{ADH} 3$ enzymes are also active in HMGSH oxidation and GSNO reduction, with similar reductive vs. oxidative ratios than that for amphioxus enzyme: 2.3 and 1.9 times fold, respectively [14]. The comparison of human, amphioxus and yeast supports the reported constancy at the functional and structural level of class 3 enzymes [24, 25].

Figure 1. Amphioxus total protein homogenate $(1.0 \mathrm{mg})$ resolved on non-denaturing $7.5 \%$ polyacrylamide gel electrophoresis and stained for formaldehyde dehydrogenase (lane 1) and GSNO reductase (lane 2) activities. Coomassie stained SDS/PAGE of samples corresponding to the different purification steps of recombinant $B$. floridae ADH3: $40 \mu \mathrm{g}$ of total protein homogenate (soluble fraction) from an $E$. coli expressing $B$. floridae ADH3 (lane 3); $16 \mu$ g of partially purified ADH3 eluted form a Talon Metal Affinity Resin (BD Biosciences Clontech, USA) after enterokinase cleavage (lane 4), and $2.3 \mu \mathrm{g}$ of pure recombinant enzyme after Superdex 200 FPLC column (lane 5). Pure recombinant protein $(2.0 \mu \mathrm{g})$ was loaded onto non-denaturing $7.5 \%$ polyacrylamide gel electrophoresis and stained for formaldehyde dehydrogenase (lane 6) and GSNO reductase (lane 7) activity

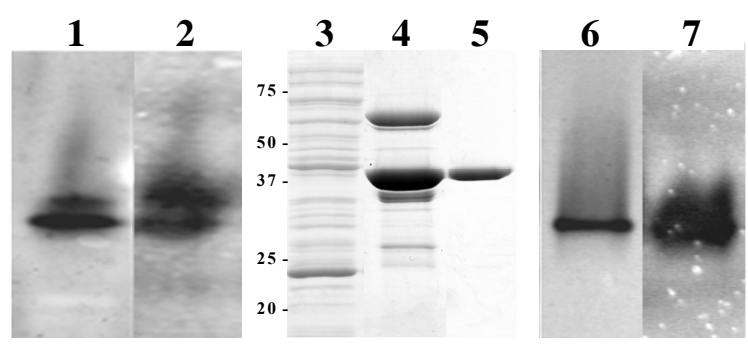


Table 1. GSNO and HMGSH activities of ADH3.

\begin{tabular}{|c|c|c|c|c|c|c|c|c|c|}
\hline & & B. floridae $^{a}$ & B. lanceolatum & Drosophila & Rat & Human & Human $^{1}$ & Human $^{2 a}$ & S. cerevisiae ${ }^{a}$ \\
\hline \multirow[t]{3}{*}{ GSNO } & $\mathrm{Km}(\mathrm{mM})$ & $0.056 \pm 0.009$ & - & - & 0.028 & - & 0.027 & 0.027 & 0.15 \\
\hline & kcat (min-1) & $10000 \pm 520$ & - & - & 2640 & - & 2400 & 12000 & 52600 \\
\hline & kcat/Km & $178800 \pm 25100$ & - & - & 94300 & - & 90000 & 444400 & 350000 \\
\hline NADH & $\mathrm{Km}(\mathrm{mM})$ & $0.045 \pm 0.011$ & - & - & 0.024 & - & 0.008 & 0.03 & 0.13 \\
\hline \multirow[t]{3}{*}{ HMGSH } & [ $\mathrm{Km}(\mathrm{mM})$ & $0.004 \pm 0.0006$ & 0.0044 & 0.006 & - & 0.004 & 0.002 & 0.0014 & 0.02 \\
\hline & kcat (min-1) & $375 \pm 16$ & 680 & 960 & - & 200 & 115 & 320 & 3100 \\
\hline & kcat/Km & $87900 \pm 9667$ & 150000 & 160000 & - & 50000 & 58000 & 229000 & 155000 \\
\hline NAD & $\mathrm{Km}(\mathrm{mM})$ & $0.008 \pm 0.0018$ & 0.011 & 0.13 & - & 0.009 & 0.007 & 0.007 & 0.045 \\
\hline
\end{tabular}

Values are from this work (B. floridae ADH3) or from the literature (B. lanceolatum, Drosophila and Human ([17] and references therein); Rat [12]; Human $^{1}$ [26]; Human ${ }^{2}$ and $S$. cerevisiae [14]). ${ }^{a}$ These values are from recombinant expressed enzymes.

\section{Amphioxus nitric oxide synthase: phylogeny and immunodetection}

To link the GSNOR activity of ADH3 with the production of NO/GSNO, we searched for amphioxus NOS sequences in databases and retrieved a B. floridae cDNA (AF396968) with clear homology with vertebrate Nos genes. This sequence matched to a unique Nos gene that was assembled from the available raw data of the amphioxus genome project. Comparison of the cDNA and the genomic sequences showed minor differences that were corrected to maximize the similarity with known NOS enzymes and allowed us to deduce the gene structure. The $B$. floridae Nos gene was made of 26 exons that expanded over $9.5 \mathrm{~kb}$ (data not shown), encoding a 1329 aa protein (Figure 2A) equally related with the three iNOS, eNOS and nNOS- vertebrate forms. In accordance, in the phylogenetic tree, amphioxus NOS branched outside the clade comprising all vertebrate NOS (Figure 2B). This topology would be in agreement with a single Nos gene in an ancestral chordate.

NOS protein in adult amphioxus extracts was detected by western blot (Figure 3G) using an affinity purified rabbit anti-NOS antibody that specifically recognises a C-terminal epitope, DQKRYHEDIFG, highly conserved among NOS isoforms in vertebrates, insects and crustaceans $[7,22]$. The deduced $B$. floridae sequence for this epitope is: DNNRYHEDIFG. Two immunoreactive bands of approximately $140 \mathrm{kDa}$ and $110 \mathrm{kDa}$ were detected in adult amphioxus extracts
(Figure 3G). Band multiplicity could correspond to two protein isoforms generated by alternative splicing of NOS transcripts, as reported for mouse, human and Drosophila NOS [27, 28], or to proteolytic cleavage at the N-terminal domain [29]. Whole-mount immunostaining showed NOS expression also during amphioxus development. While no obvious staining other than background was observed at early developmental stages (data not shown), B. floridae $48 \mathrm{~h}$ larvae showed a strong signal confined to the midand hindgut of the developing intestine and the dorsal region of the club-shaped gland (csg), an enigmatic secretory organ located on the right side of the larval pharynx between the endostyle and the anterior-most pharyngeal gill slit (Figure 3, A and B). In the first, the NOS signal was separated by a nonstained segment, which corresponds to the ilio-colon ring, an specialized region with conspicuous cilia that contributes to the food cord passage. Confocal sections revealed a left-right NOS asymmetry in the midgut area (Figure 3, C-E), with a triangular region at the left side devoid of signal that corresponds to the lateral ciliated tract. Concerning cgs expression, although the dorsal and ventral cells are not morphologically different, the specific NOS expression to the dorsal area reveals functional differences along the dorsal-ventral axis, as reported for other amphioxus genes, e.g. Krox [30] and crabp [31] to the dorsal region, and maf [31] and BbPtx [32] to the ventral duct.

Figure 2. (A). Comparison of the deduced amino acid sequences of $B$. floriade NOS (Bf NOS) with human (Hs nNOS, iNOS and eNOS) and Drosophila (Dm NOS) forms. Strictly conserved and highly conserved residues (>60\%) are shown in black background, and similar residues in gray. Defined binding domains (as in [27]) are overlined in red: cofactor-binding sites for heme (1), calmodulin (2), FMN (3), FAD pyrophosphate (4), FAD isoalloxazine (5), NADPH ribose (6), NADPH adenine (7) and the C-terminal conserved NADPH binding sequence (8). The sequence used for phylogenetic analyses begins at position D352 of human nNOS $(*)$. (B) Phylogenetic reconstruction of NOS enzymes. Figures at nodes are the scores from 1000-bootstraps resampling of the data (NJ, in black) or quartet puzzling supports values (ML, in red). Ac, Aplysia californica, California sea hare; As, Anopheles stephensi; Bm, Bombix mori; Cc, Cyprinus carpio, carp; Dr, Danio rerio, zebrafish; Dm, Drosophila melanogaster; Gg, Gallus gallus; Hs, Homo sapiens; Ls, Lymnaea stagnalis, great pond snail; Ms, Manduca sexta, tobacco hornworm; Mm, Mus musculus; Om, Oncorhynchus mykiss, rainbow trout; Rr, Rattus norvergicus, Rp, Rhodnius prolixus, insect; Sp, Strongylocentrotus purpuratus, sea urchin, Tp, Takifugu poecilonotus; Xt, Xenopus tropicalis. 
A)

HS-nNOS MEDHMFGVOOIOPNVISVRLFKRKVGGLGFLVKERVSKPPVIISDLIRGGAAEOSGLIOAGDIILAVNGRPLVDLSYDSALEVLRGIASETHVVLILRGPEGFTTHLETTFTGDGTPKTI 120

Hs-iNOS

Bs-eNOS

Q

46

-AQQQQQQQQQQQLQQQQQQLQQQKAQTQQQNSRKIK----10

HS-NNOS RVTQPLGPPTKAVDLSHQPPAGKEQPLAVDGASGPGNGPQHAYDDGQEAGSLPHANGLAPRPPGQDPAKKATRVSLQGRGENNELLKGIEPVLSLLTSGSRGVKGGAPAKAEMKDMGIQV 240

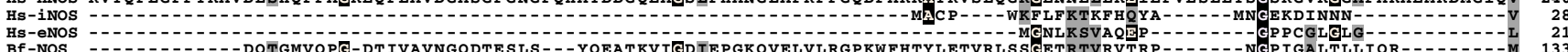

HS-eNOS
BE-NOS -
DM-NOS -

HS-nNOS DRDLDGKSHKPLPLGVENDRVFNDLWGKGNVPVVLNNPYSEKEQPPTSGKQSPTKNGSPSKCPRFLKVKNWETEVVLTDTLHLKSTLETGCTEYICMGSTMHPSQHARRPE-DVRTKGQT 359 HS-INOS EKAPCATSS-PVTQDDLQYHNLSKQQNESPQPLV--- -ETGKKSPESLVKLD--- -ATPLSSPRHVRIKNWGSGMTF QDTLHHKAKGILTCRSKSCLGS IMTPKSLTRGPRDKPTPPDEI 139

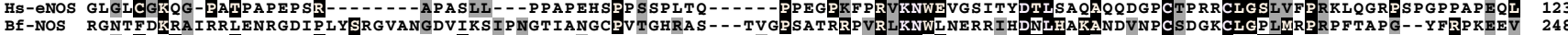

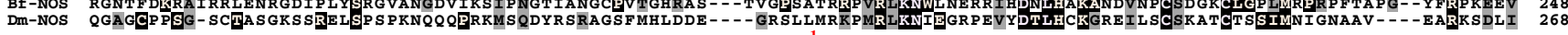

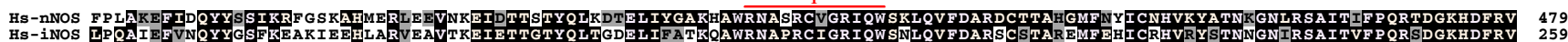

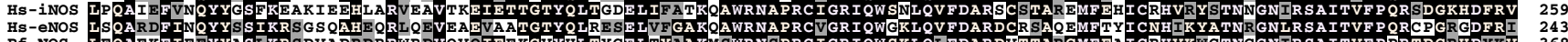

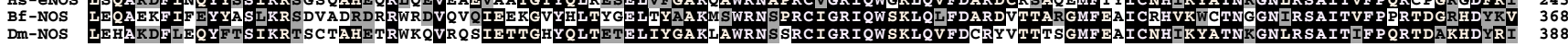
HS-nNOS WNSQLIRYAGYKQPDGSTLGDPANVQFTIICTQQGWKPPRGRFDVLPLLLQANGNDPELFOTPPELVLEVPIRHPKFEWFKDLGLKWYGLPAVSNMLLEIGGLEFSACPFSGWYMGTEIG 599

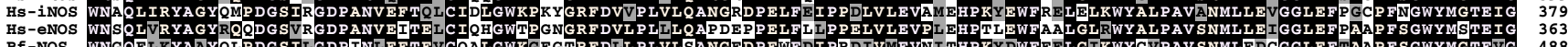

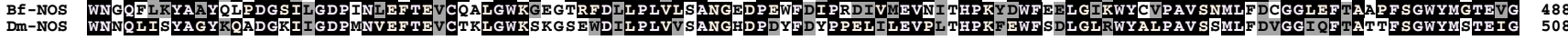

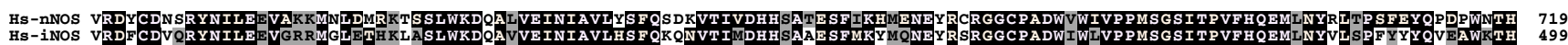

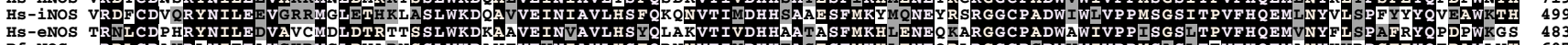

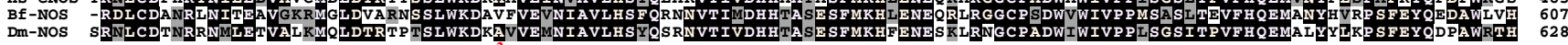
HS-nNOS VWRG--1-2- TNGTPTKRRAIGFKKLAAEAVKFSARLMGQAMAKRVKATILYATETGKSQAYAKTLCEIFKHAFDAKVMSMEEYDIVHLEHETLVLVVTSTFGNGDPPENGEKFGCA 829

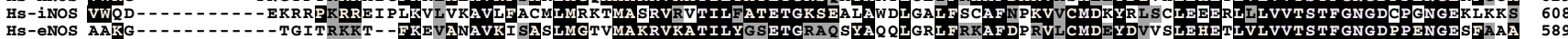

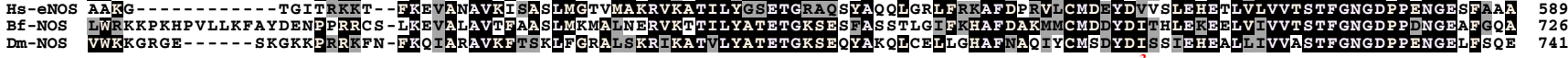
DM-NOS HS-nNOS LWEMN LFML-

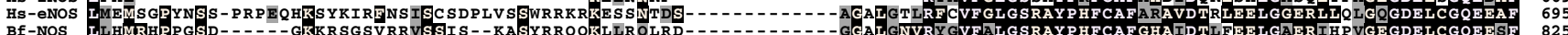

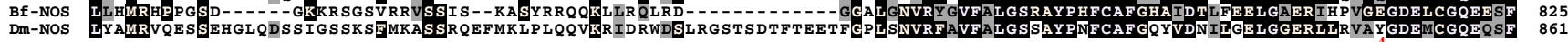

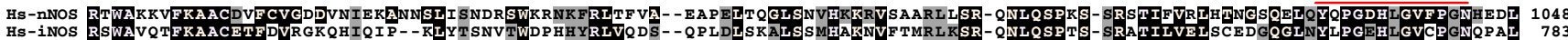

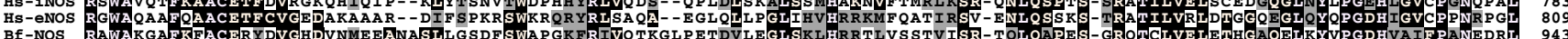

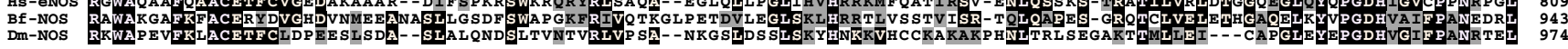

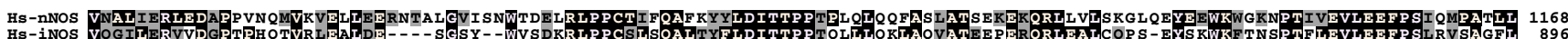

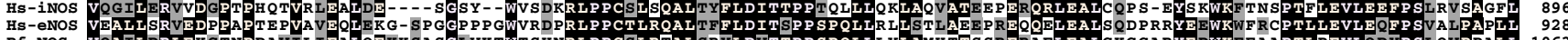

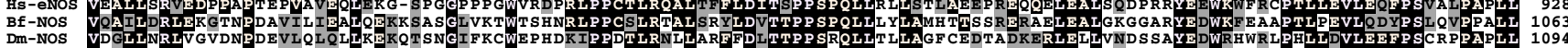
HS-nNOS TTQLSLLQPRYYSISSSPDMYPDEVHLTVAIVSYRTRDGEGPIHHGVCSSWLNRIQADELVPCFVRGAPSFHLPRNPQVPCILVGPGTGIAPFRSFWQ- - QRQFDTQHKG---MNPCPMV 1283
HS-INOS LSOLPILKPRFYSISSSRDHTPTEIHLTVAVVTYHTRDGOGPLHHGVCSTWLNSIKPODPVPCFVRNASGFHLPEDPSHPCILIGPGTGIAPFRSFWO--ORLHDSOHKG---VRGGRMT 1011

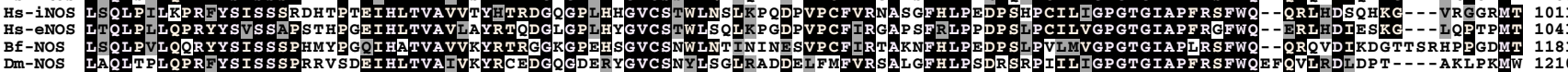
HS-nNOS LVFGCRQSKIDHIYREFTLQAKKNKGVFRELYTAYSREPDKPKKYVQDILQEQLAESVYRATKEQGGHIYVCGDVTMAADVVLAIQRTMTQQGKLSAEDAGVFTSRMRDDNRYHEDIFGVT 1403 HS-INOS LVFGCRRPDDHIYQEEMLEMARGVLHAVHTAYSRLPGKPKVYVQDILRQQLASEVIRVIHKGPGHIYVCGDVRMARDVAHTLKQLVAAKLKLNEEQVEDYFFQTKSQKRYHEDIFGAV 113

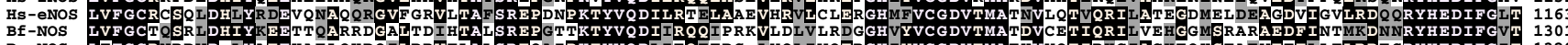

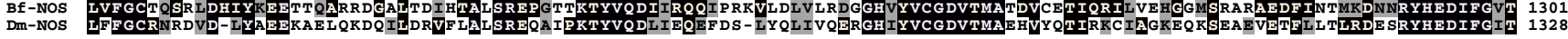

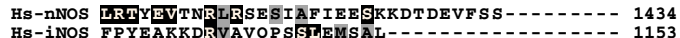
HS-INOS FPYEAKKDRVAVQPSSLEMSALHS- NOS LRTQEVTSRIRTQSFSLQERQLRGAVPWAFDPPGSDTNSP 1203
BA-NOS LKTHEVENEARKRGMSLIVTSDDEDTSL-

B)

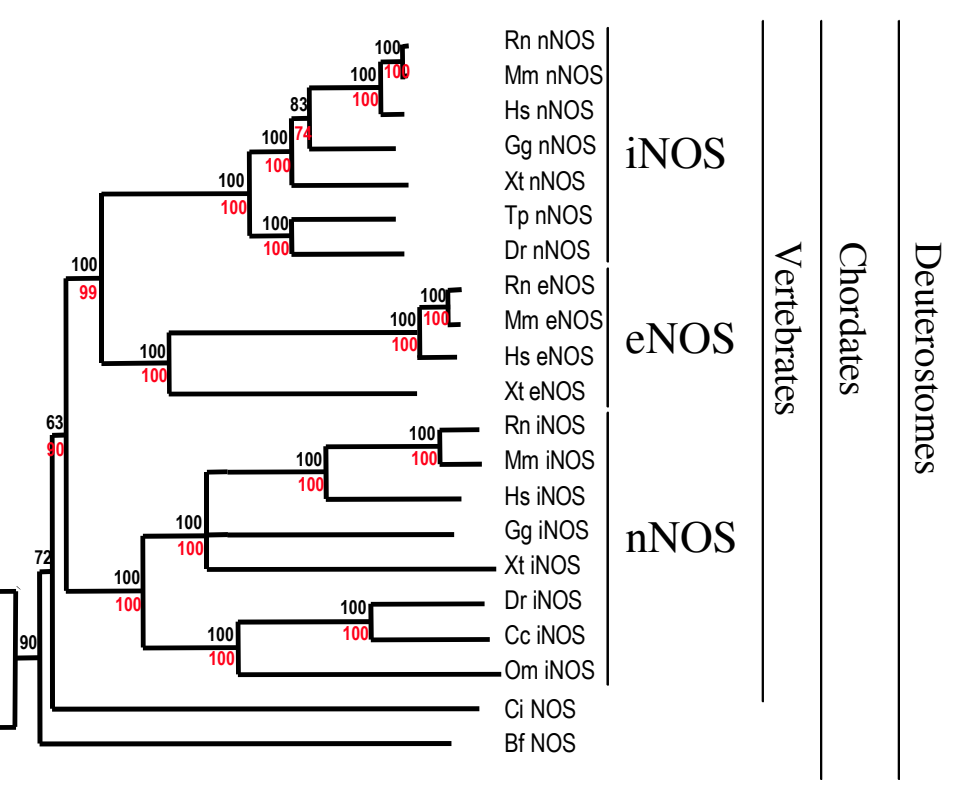


Figure 3. Whole-mount immunostaining of $48 \mathrm{~h}$ B. floridae larvae with an anti-NOS antibody. (A) Right-sided view. NOS signalling in the developing midgut and hindgut region separated by a non stained area, the ilio-colon ring (arrow), and in the dorsal region of the club-shaped gland (arrowhead). (B) Left-sided view. NOS signalling in the gut shows two non stained regions, which correspond to the ilio-colon ring (arrow) and to the lateral ciliated tract (double arrowhead). (C-E) Magnified view of the confocal sections of the right side, light and left side of the gut, respectively, showing left-right asymmetry in NOS localization. (F) Detail of the NOS staining in the dorsal region of the club-shaped gland (arrowhead). (G)Western blot analysis of amphioxus protein extracts. A total of $1.0 \mathrm{mg}$ of soluble protein extract were resolved by electrophoresis on a SDS-7.5\% polyacryla-mide gel, transferred to a polyvinylidene difluoride (PVDF) membrane and incubated with an anti-NOS antibody. Positions of molecular mass markers (in kDa) are shown on the left. (H) Adh3 expression visualized by whole-mount in situ hybridization as reported in [17].

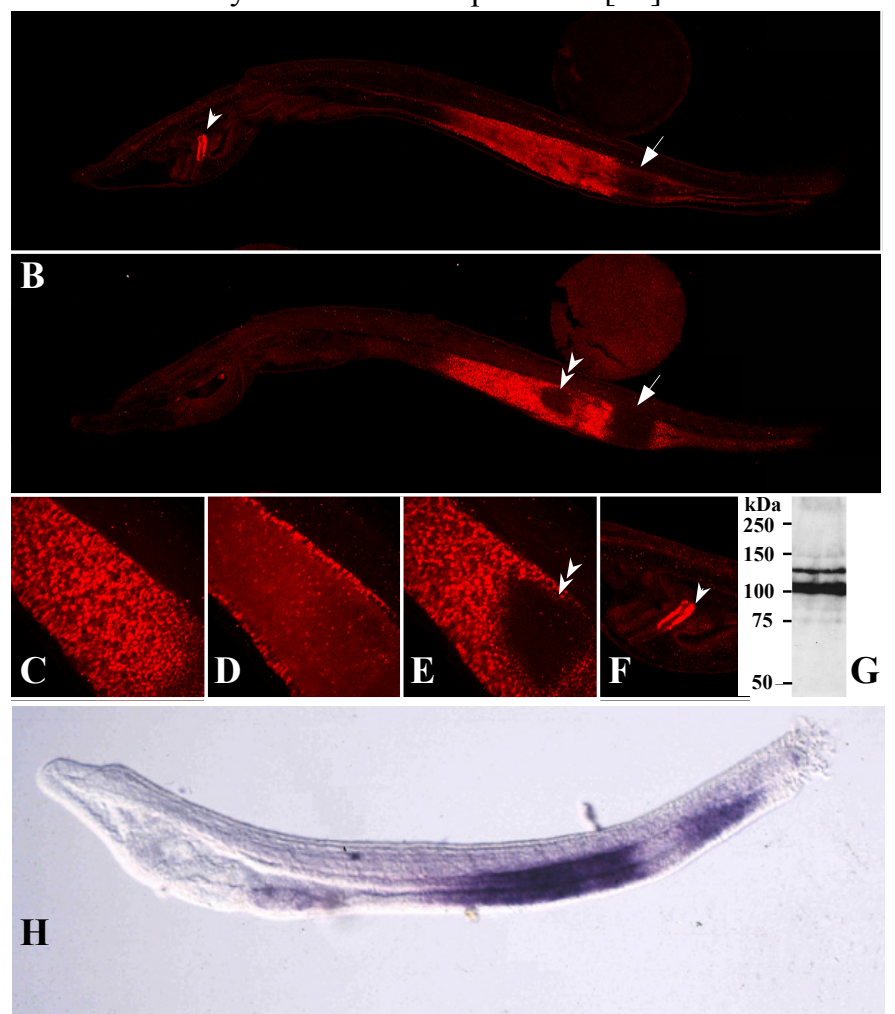

\section{Discussion}

The housekeeping role long attributed to ADH3 as a formaldehyde detoxificating enzyme has been lately challenged after in situ analyses and studies on the activity of the enzyme. Concerning expression, the tissue-specificity observed for $\mathrm{ADH} 3$ in amphioxus and other invertebrates [17, 18] was difficult to reconcile with the assumed general cytoprotective role for this enzyme. In relation to the biochemical activity, human and rat ADH3 used substrates other than formaldehyde, such as GSNO [12, 14, 26]. Moreover, we here show a GSNOR activity for the recombinant $B$. floridae $\mathrm{ADH} 3$, 2-fold higher that for HMGSH (Table 1), and preservation of the ADH3 kinetic features during the invertebrate/vertebrate transition, when the ADH family expanded considerably through a series of duplications [25]. Based on the strict preservation of the protein structure and the biochemical activities, including those shown in the present study, we assume that the ancestral ADH3 was a multifunctional enzyme, active in HMGSH and GSNO metabolisms.

The biochemical data pointed to a functional role for the cephalochordate $\mathrm{ADH} 3$ in the $\mathrm{NO}$ homeostasis. To link the $\mathrm{ADH} 3$ gut-restricted expression with the NO/GSNO production, we aimed at characterizing the amphioxus Nos genes. Surveys of B. floridae databases rendered a single-copy Nos that showed gut-specific expression in developing larvae. Phylogenetically, the amphioxus NOS protein branched outside the clade that comprised all the vertebrate forms, indicating that the Nos duplications took place after the cephalochordate divergence. The topology of the tree also suggested that Nos duplicated at least twice during vertebrate evolution: the $\mathrm{nNOS}$ enzymes aroused after the first duplicative event, while the iNOS and eNOS were generated after the second. The increase in complexity, probably concomitant with novel areas of NO production, could be linked to the almost generalized ADH3 expression observed in vertebrates [18, 33] and improved the regulation of NO/GSNO homeostasis.

In situ and immunostaining analyses in amphioxus revealed an almost full overlap of the ADH3 and NOS expression patterns and showed the larval intestine as the major organ for $\mathrm{NO}$ synthesis and degradation. In vertebrates, the in vivo contribution of $\mathrm{ADH} 3$ in $\mathrm{NO}$ metabolism was established in $\mathrm{ADH} 3$ knockout mice, whose major 
functional alteration was an increase in intracellular SNO-protein levels under basal conditions [9, 11], effect that was greatly enhanced after endotoxic or bacterial challenge. During host defence responses, vertebrate iNOS is strongly induced [34, 35] and Snitrosothiols are currently involved to respond to cryptococcal, salmonella and tuberculous infections [36-38]. NO is also involved in the molluscan [39] and Drosophila [40] defence systems that, in the latter, are thought to originate mainly in the fat body, where Drosophila ADH3 is also strongly expressed [18]. Overall, the overlapping signals of amphioxus ADH3 and NOS (compare panels A and B with $\mathrm{H}$ in Figure 3) could account for a GSNO anti-microbial activity in the gut, where the first host-pathogen interaction takes place, and it is therefore prone to bacterial infections.

\section{Acknowledgements}

The authors acknowledge the critical comments raised by the reviewers that have substantially improved the scope of the discussion section. This work was supported by Ministerio de Ciencia y Tecnología (Spain), grant BMC2003-05211. LG was awarded FPI fellowship from CIRIT (Generalitat de Catalunya).

\section{Conflict of interest}

The authors have declared that no conflict of interest exists.

\section{References}

1. Feelisch M, Martin JF. The early role of nitric oxide in evolution. Trends Ecol Evol 1995; 10:496-499.

2. Stamler JS, Lamas S, Fang FC. Nitrosylation. the prototypic redox-based signaling mechanism. Cell 2001; 106:675-683.

3. Colasanti M, Venturini G, Merante A, et al. Nitric oxide involvement in Hydra vulgaris very primitive olfactory-like system. J Neurosci 1997; 17:493-499.

4. Frogget SJ, Leise EM. Metamorphosis in the marine snail Ilyanassa obsoleta, Yes or NO? Biol Bull 1999; 196:57-62.

5. Giovine M, Pozzolini M, Favre A, et al. Heat stress-activated, calcium-dependent nitric oxide synthase in sponges. Nitric Oxide 2001; 5:427-431.

6. Koh HY, Jacklet JW. Nitric oxide induces cGMP immunoreactivity and modulates membrane conductance in identified central neurons of Aplysia. Eur J Neurosci 2001; 13:553-560.

7. Kim HW, Batista LA, Hoppes JL, et al. A crustacean nitric oxide synthase expressed in nerve ganglia, Y-organ, gill and gonad of the tropical land crab, Gecarcinus lateralis. J Exp Biol 2004; 207:2845-2857.

8. Regulski M, Stasiv Y, Tully T, et al. Essential function of nitric oxide synthase in Drosophila. Curr Biol. 2004; 14:R881-882.

9. Liu L, Yan Y, Zeng M, et al. Essential roles of S-nitrosothiols in vascular homeostasis and endotoxic shock. Cell 2004; 116:617628.

10. Hess DT, Matsumoto A, Kim SO, et al. Protein S-nitrosylation: purview and parameters. Nat Rev Mol Cell Biol 2005; 6:150-166.

11. Liu L, Hausladen A, Zeng M, et al. A metabolic enzyme for Snitrosothiol conserved from bacteria to humans. Nature 2001; 410:490-494.

12. Jensen DE, Belka GK, DuBois GC. S-Nitrosoglutathione is a substrate for rat alcohol dehydrogenase class III isoenzyme. Biochem J 1998; 2:659-668.
13. Sakamoto A, Ueda M, Morikawa H. Arabidopsis glutathionedependent formaldehyde dehydrogenase is an Snitrosoglutathione reductase. FEBS Lett 2002; 515:20-24.

14. Fernandez MR, Biosca JA, Pares X. S-nitrosoglutathione reductase activity of human and yeast glutathione-dependent formaldehyde dehydrogenase and its nuclear and cytoplasmic localisation. Cell Mol Life Sci 2003; 60:1013-1018.

15. Koivusalo M, Baumann M, Uotila L. Evidence for the identity of glutathione-dependent formaldehyde dehydrogenase and class III alcohol dehydrogenase. FEBS Lett 1989; 257:105-109.

16. Gonzàlez-Duarte R, Albalat R. Merging protein, gene and genomic data: the evolution of the MDR-ADH family. Heredity 2005; 95:184-197.

17. Cañestro C, Hjelmqvist L, Albalat R, et al. Amphioxus alcohol dehydrogenase is a class 3 form of single type and of structural conservation but with unique developmental expression. Eur J Biochem 2000; 267:6511-6518.

18. Cañestro C, Godoy L, Gonzàlez-Duarte R, et al. Comparative expression analysis of Adh3 during arthropod, urochordate, cephalochordate and vertebrate development challenges its predicted housekeeping role. Evol. Dev. 2003; 5:157-162.

19. Uotila L, Koivusalo M. Multiple forms of formaldehyde dehydrogenase from human red blood cells. Hum Hered 1987; 37:102-106.

20. Thompson JD, Gibson TJ, Plewniak F, et al. The CLUSTAL_X windows interface: flexible strategies for multiple sequence alignment aided by quality analysis tools. Nucleic Acids Res 1997; 25:4876-4882.

21. Page RDM. TREEVIEW: An application to display phylogenetic trees on personal computers. Comput. Appl. Biosci 1996; 12:357-358.

22. Pollock VP, McGettigan J, Cabrero P, et al. Conservation of capa peptide-induced nitric oxide signalling in Diptera. J Exp Biol. 2004; 207:4135-4145.

23. Yasui K, Tabata S, Ueki T, et al. Early development of the peripheral nervous system in a lancelet species. J Comp Neurol 1998; 393:415-425.

24. Danielsson O, Atrian S, Luque T, et al. Fundamental molecular differences between alcohol dehydrogenase classes. Proc Natl Acad Sci USA 1994; 91:4980-4984.

25. Cañestro C, Albalat R, Hjelmqvist L, et al. Ascidian and Amphioxus Adh genes correlate functional and molecular features of the ADH Family expansion during vertebrate evolution. J Mol Evol 2002; 54:81-89.

26. Hedberg JJ, Griffiths WJ, Nilsson SJ, et al. Reduction of Snitrosoglutathione by human alcohol dehydrogenase 3 is an irreversible reaction as analysed by electrospray mass spectrometry. Eur J Biochem. 2003; 270:1249-1256.

27. Regulski M, Tully T. Molecular and biochemical characterization of dNOS: a Drosophila Ca2+/calmodulindependent nitric oxide synthase. Proc Natl Acad Sci USA 1995; 92:9072-9076.

28. Ogura T, Yokoyama T, Fujisawa H, et al. Structural diversity of neuronal nitric oxide synthase mRNA in the nervous system. Biochem Biophys Res Commun. 1993; 193:1014-1022.

29. Sengupta R, Sahoo R, Mukherjee S, et al. Characterization of Drosophila nitric oxide synthase: a biochemical study. Biochem Biophys Res Commun. 2003; 306:590-597.

30. Knight RD, Panopoulou GD, Holland PW, et al. An amphioxus Krox gene: insights into vertebrate hindbrain evolution. Dev Genes Evol 2000; 210:518-521.

31. Jackman WR, Mougey JM, Panopoulou GD, et al. crabp and maf highlight the novelty of the amphioxus club-shaped glan. Acta Zool 2004; 85:91-99.

32. Yasui $\mathrm{K}$, Zhang $\mathrm{S}$, Uemura $\mathrm{M}$, et al. Left-right asymmetric expression of BbPtx, a Ptx-related gene, in a lancelet species and 
the developmental left-sidedness in deuterostomes. Development 2000; 127:187-195.

33. Ang HL, Deltour L, Hayamizu TF, et al. Retinoic acid synthesis in mouse embryos during gastrulation and craniofacial development linked to class IV alcohol dehydrogenase gene expression. J Biol Chem 1996; 271:9526-9534.

34. Laubach VE, Foley PL, Shockey KS, et al. Protective roles of nitric oxide and testosterone in endotoxemia: evidence from NOS-2-deficient mice. Am J Physiol. 1998; 275:H2211-2218.

35. Nicholson SC, Hahn RT, Grobmyer SR, et al. Echocardiographic and survival studies in mice undergoing endotoxic shock: effects of genetic ablation of inducible nitric oxide synthase and pharmacologic antagonism of platelet-activating factor. J Surg Res. 1999; 86:198-205.

36. De Groote MA, Testerman T, Xu Y, et al. Homocysteine antagonism of nitric oxide-related cytostasis in Salmonella typhimurium. Science. 1996; 272:414-417.

37. MacMicking JD, North RJ, LaCourse R, et al. Identification of nitric oxide synthase as a protective locus against tuberculosis. Proc Natl Acad Sci USA. 1997; 94:5243-5248.

38. de Jesus-Berrios M, Liu L, Nussbaum JC, et al. Enzymes that counteract nitrosative stress promote fungal virulence. Curr Biol 2003; 13:1963-1968.

39. Conte A, Ottaviani E. Nitric oxide synthase activity in molluscan hemocytes. FEBS Lett. 1995; 365:120-124.

40. Foley E, O'Farrell PH. Nitric oxide contributes to induction of innate immune responses to gram-negative bacteria in Drosophila. Genes Dev. 2003; 17:115-125. 